\title{
DOCUMENTING ETHNOBOTANICAL KNOWLEDGE OF RURAL COMMUNITY FOR SUSTAINABLE BENEFITS
}

\author{
Jovita Elderson Ripen $^{1}$ and Gabriel Tonga Noweg ${ }^{2}$ \\ ${ }^{1}$ Faculty of Resource Science and Technology, Universiti Malaysia Sarawak, \\ 94300 Kota Samarahan \\ ${ }^{2}$ Institute of Biodiversity and Environmental Conservation, Universiti Malaysia \\ Sarawak, 94300 Kota Samarahan \\ 1jovitaelderson@yahoo.com; 2 gtnoweg@unimas.my
}

Received: 8 Feb 2017 Accepted: 30 May 2017 Published: 30 June 2017

\begin{abstract}
A study was conducted to identify and document all plants with economic and cultural significance to the nine Singai Bidayuh communities (villages) around the foothills of Mount Singai. Key informant surveys were carried out in each of the villages prior to field documentation and collection of specimens for identification. The information on use and methods of preparations and applications were obtained from active practitioners or traditional "medicine men" and "medicine women" through interviews and application observations for medicinal plants. For each of the plant species identified, specific use, parts of the plant used, method of preparation and applications, and general precautionary notes were included. A total of 52 species of useful plants were documented for medicine and the remaining were for food, preservatives, and spiritual healing. A use and valuation survey on these plant species also revealed that the total value of traditional medicinal plant use for the Singai Bidayuh community based on the current rate of household participation of 10\% is at RM15,443.90 per year. The results have provided a baseline on the economic value of the forest resources and contributed towards a better management of the area as a community heritage.
\end{abstract}

Keywords: Forest resources; traditional medicine; Bidayuh communities; medicinal plants; traditional knowledge; valuation of medicinal plants; economic value

\section{INTRODUCTION}

For generations, knowledge and use of plants in healing were passed down through the oral tradition. Traditional livelihood which centered on forest foraging and subsistence farming had kept native communities attached to the skills and knowledge of this gift of nature. Prior to the Malaysian Independence, there were hardly any serious efforts to document the use of wild plants, especially for food and medicinal purposes among the native communities. As 